\title{
Severe Form of the Hydrothorax Associated with Right Divided Atrium and Cytomegalovirus Infection - Prenatal Diagnosis and Outcomes
}

\author{
Ramush A. Bejiqi $i^{1,2,3}$, Ragip Retkoceri ${ }^{3}$, Hana Bejiqi ${ }^{4}$, Naim Zeka ${ }^{3}$, Abdurrahim Gerguri $^{3}$, Armend Vuciterna $^{3}$, Arlinda Maloku $^{3}$, \\ Aferdita Mustafa $^{3}$, Rinor Bejiqi ${ }^{3 *}$ \\ ${ }^{1}$ Texas Health Science Center, San Antonio, Texas, USA; ${ }^{2}$ Medical School, University of Gjakova, Gjakova, Republic of \\ Kosovo; ${ }^{3}$ Pediatric Clinic, University Clinical Center of Kosovo, Prishtina, Republic of Kosovo; ${ }^{4}$ Main Center of Family Medicine, \\ Prishtina, Republic of Kosovo
}

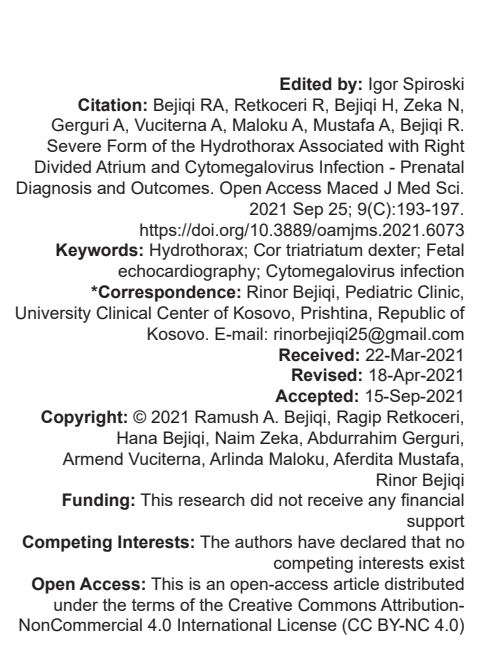

\begin{abstract}
BACKGROUND: Fetal hydrothorax $(\mathrm{FH})$ or pleural effusion is a clinical entity, and refers to accumulation of fetal pleural fluid, which may presents a wide spectrum of severity ranging from small, harmless effusion, to life-threatening thoracic compression. The perinatal mortality associated with pleural effusion is at least $50 \%$. Cardiac and extracardiac abnormalities may accompany the hydrothorax and their presence also affects the prognosis. Division of the right atrium, first reported in 1868, also known as cor triatriatum dexter, is extremely a rare congenitally abnormality, in which persistence of right valve of the embryonic systemic venous sinus divides the right atrium into two chambers. The embryonic valvar structures, whose significance during fetal life is to direct the richly oxygenated inferior caval venous blood across to the left atrium and thence to the aorta, normal regress in late fetal life and early childhood. Cytomegalovirus (CMV) is a common human virus, member of herpes virus family, and the most common cause of intrauterine infection, occurring in $0.2-2.2 \%$ of life births.

CASE REPORT: This report describes antenataly diagnosed a case of a divided right atrium, associated with severe form of hydrothorax and CMV infection. Here, we present a fetus with sever hydrothorax associated with divided right atrium and CMV infection.

CONCLUSION: Basing on the published data, CCT is an uncommon condition which is still associated with a poor outcome. However, advances in fetal medicine, including prenatal diagnosis by itself together with the option in selected cases of scheduled fetal extraction and/or antenatal therapy, and in neonatal medicine including rapid postnatal intervention, sophisticated ventilator support are improving the prognosis of these patients and nowadays most of them are likely to survive.
\end{abstract}

\section{Introduction}

Congenital chydrothorax (CCT), sometimes referred to as primary fetal effusion, is defined as the accumulation of fluid in the pleural cavity. It is the most common type of pleural effusion in fetal life and the most frequent cause of neonatal pleural effusion leading to respiratory distress in the newborn [1], [2]. Fetal hydrothorax $(\mathrm{FH})$ is a rare disorder but with increased awareness and widespread usage of antenatal ultrasound, pleural effusion is likely to be diagnosed more frequently. However, the natural history of this disease entity is not well understood and the prognosis remains variable [3]. The true incidence of fetal pleural effusions is unknown but there have been estimates of an incidence of 1 in 10,000 to 1 in 15,000. The perinatal mortality associated with pleural effusion is at least $50 \%$ [4], [5]. Division of the right atrium (prominence of Eustachian and Thebesian valves) is recognized pathologically, but is rare. This dividing portion is placed between the systemic venous sinus and the distal part of the right atrium, made up of the vestibule and appendage. Before the application of echocardiography most reported examples have been presented as case reports subsequent to diagnosis postmortem. Despite many attempts, we have not found any reported cases diagnosed in antenatal period.

\section{Case Report}

A 28-year-old pregnant woman, on her fifth pregnancy (three abortions and one normal delivery) was referred to our pediatric cardiology unit at the $37^{\text {th }}$ week of gestation because, during the routine obstetric echosonographic examination, massive hydrothorax in both sides was detected. She had lost her previous fetuses at the $26^{\text {th }}, 28^{\text {th }}$, and $32^{\text {nd }}$ gestational weeks in her first, second, and forth pregnancies. Despite 
these abortions, so far laboratory tests have not been performed, particularly tests for TORCH infections.

At first glance, fetal echocardiography revealed normal heart size and position, where the chest space is filled with free liquid and the lungs are contracted to the mediastinum. Detailed multi-planar scanning showed that the atrial septum was aneurysmatic, allowing a little right to left shunt, large peri-membranous ventricular septal defect and tiny membrane across right atrium, dividing it in two parts. There were not recorded signs of any other malformations, including polyhidramnion or hydrops (Figures 1 and 2).

Instantly routine lab analysis and analysis for TORCH screening were performed. Cytomegalovirus (CMV) is a common human virus. Antibodies to CMV are evidence of a current or past infection. In our case lab analysis from amniotic fluid showed positive of CMV early antigen antibody (high level of CMV Immunoglobulin $\mathrm{G}$ and $\mathrm{M}$ antibody). Detection was done using assays EIA test with polystyrene, and colorimetric detection system: Latex, nanogold, and/ or iron solid phases using different detection system (colorimetric, chaemyluminescent)

The fetus was followed weekly for fetal decompensation and signs of hydrops till the $39^{\text {th }}$ week of gestation, and then normally delivery were performed. The male infant who was $3245 \mathrm{~g}$ at birth, with Apgar-score 3. 0. 0; oxygen saturation, measured by pulse oxymetri, was $82 \%$, immediately after delivery was intubated. Echo- guided thoracocentesis was performed to draw $82 \mathrm{ml}$ of golden/yellow pleural effusion liquid. Initially, cross-sectional echocardiography showed normal heart function. X-ray chest shoved retraction of the lungs in both sides of the heart. Unfortunately, the patient died $2 \mathrm{~h}$ after delivery due to intractably pulmonary non expansion and low cardiac output syndrome.

\section{Discussion}

$\mathrm{FH}$ or pleural effusion is a clinical entity, which may be idiopathic (primary) or secondary to a variety of disorders such as cardiac, pulmonary and gastrointestinal malformation, infection, hematological, and chromosomal abnormalities or as a part of immune hydrops. The first case of fetal pleural effusion was described by Carroll [4]. On meta-analysis of 204 cases with hydrothorax, from 64 different centers, conducted from Aubard et al. have been analyzed mean time of detection, clinical course depending from unilateral or both sides involvement, present of hydrops and polyhydramnions. This multi-variety analysis has shown that hydrops was the only factor, independent of bilateral effusion and gestational age at the time of delivery, responsible for predicting poor outcome [6], [7]. Our case was diagnosed at 37 weeks of gestations.
The clinical course of CCT is highly variable and may range from spontaneous resolution to a progressive increase and the development of hydrops fetalis and in utero death. Similarly, if the CCT is severe and long-standing, it may lead to pulmonary hypoplasia and neonatal death. Fortunately, given that the antenatal detection of CCT is the rule; such diagnosis may allow to adequate the perinatal management. Nevertheless, although there are several treatment options for this condition, the optimal strategy is still not well defined and, certainly, CCT diagnosed in fetal life is still associated with high mortality rate of about $25-50 \%$.

Bilateral pulmonary hypoplasia associated with hydrothorax is an unexplained entity. Antenatal screening of pregnancies at risk for $\mathrm{FH}$, early detection of suspected hypoplasia and active management might afford the fetus adequate pulmonary function to support extra-uterine life. The therapeutic approach adopted in the management of $\mathrm{FH}$ is dependent on the clinical presentation. Presence of fetal distress is a medical emergency and should be managed with urgent fetal thoracocentesis. This procedure is safe and effective in an emergency. The principal drawback in this procedure is the rapid re-accumulation of fluid. It is recommended that thoracocentesis should be performed in all cases with residual fluid near term to facilitate proper lung expansion after birth [8], [9].

Pleuro - amniotic shunting involves placement of a catheter draining pleural fluid into amniotic cavity, and it's recommended if the pregnancy is less than 32 weeks. If pregnancy is more than 32 weeks, fetal thoracocentesis can be under taken since it is less invasive and has better efficacy when done between 32 and 37 weeks as compared to an earlier gestation.

Cor triatriatum dexter or partitioning of the right atrium is a rare congenital anomaly, caused by persistence of the right valve of the sinus venosus which divides atrium into two chambers: the caval veins and coronary sinus to one side and right atrial appendage on the other (the trabeculated portion) [10], [11]. The valve usually regresses early during fetal life by the $12^{\text {th }}$ week of gestation, leaving behind the crista terminalis superiorly and the Eustachian valve of the inferior vena cava and the thebesian valve of the coronary sinus inferiorly. The appearance of the valve can vary from a simple muscle bar to a fenestrated membrane or to Chiari's network as filigreed web like networks [12].

In our case, persistence of a large obstructive, membrane dividing the right atrium with small defects caused restrictive flow between "two right atrial parts" and elevated central venous pressures secondary to obstruction of the tricuspid valve, the right ventricular outflow tract, or the inferior vena cava. Associated cardiac defects, such as atrial septal defect, have been described [13]. 
When the septation is incomplete, the condition is often asymptomatic. More complete septation can cause right-side cardiac failure and elevated central venous pressure due to obstruction of the tricuspid valve, the right ventricular outflow tract or the inferior caval vein [14]. Cor triatriatum dexter is frequently associated with important abnormalities of other right cardiac structures including atrial septal defects and Ebstein's anomaly of the tricuspid valve. Cor triatriatum dexter has varying clinical manifestations depending of the degree of partitioning or septation of the right atrium [15].

Antenatally, we detected a small interatrial communication and nonrestrictive perimembranous ventricular septal defect.

Fetal pleural effusions may occur either as an isolated sonographic finding or may be part of the complex of findings seen in generalized hydrops fetalis. It could be as an isolated pleural effusions, more often seen on the right side, or bilateral isolated pleural effusions [16]. Polyhydramnios is often associated with pleural effusion, possibly due to increased intrathoracic pressure that interferes with swallowing. Isolated pleural effusions may progress to generalized hydrops fetalis. Associated abnormalities are uncommon when an isolated hydrothorax is seen. The two most common associated abnormalities are congenital diaphragmatic hernia and Trisomy 21 [17], [18].

The prognosis for every single patient remains uncertain, but factors such as bilateral effusions, fetal hydrops, associated defects, and preterm birth seem to have a negative impact in the survival rate. Tracheoesophageal fistula, extra lobar pulmonary sequestration and congenital pulmonary lymphangiectasis have also been associated with this condition [19], [20].

In our case, fetal echocardiography showed normal position of the diaphragm and, analysis of amnial liquid showed normal cariogram.

There have been numerous reports of the benefit of aspirating these effusions in utero. The major difficulty is that they often reoccur quite readily and numerous attempts will be necessary. Drainage immediately prior to delivery is often beneficial, particularly when the effusions are quite large [19].

The objective of presenting this case was to increase awareness about this common disease entity among pediatricians and obstetricians. With increasing use of antenatal ultrasound screening, an increasing number of fetal pleural effusions is likely to be diagnosed. Awareness regarding the good and bad prognostic factors would be helpful in counseling and early referral of the mother. Being aware of a recommended schema for the management of this condition would help in alleviating unnecessary anxiety among the parents and physicians. At the same time, there is a need to develop expertise in various tertiary perinatal centers to conduct procedures such as thoracocentesis and pleuroamniotic shunting [21], [22].

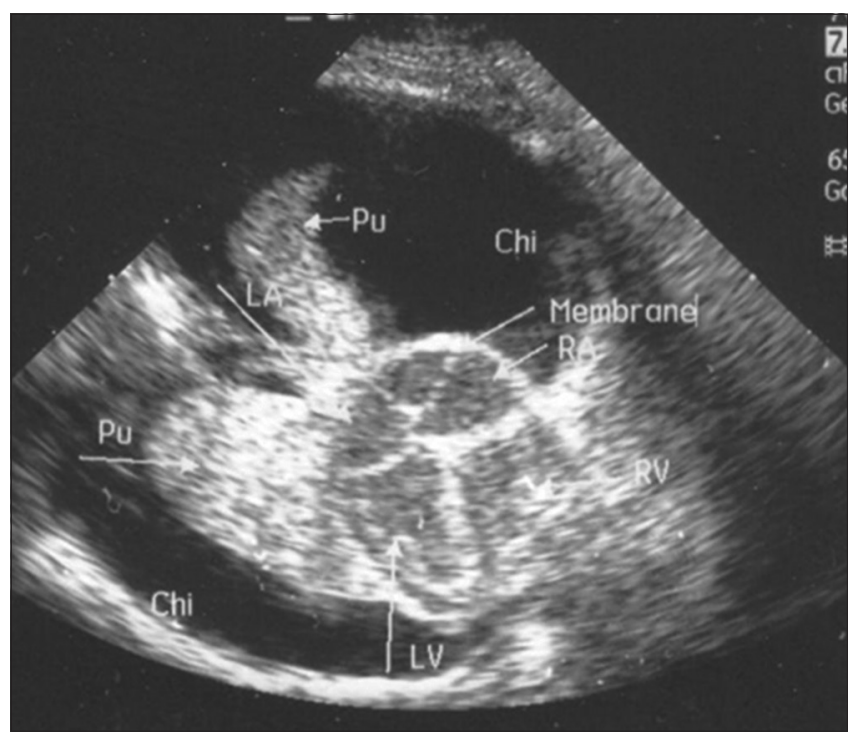

Figure 1: Four chamber view showed massive showed progression of 37 weeks of gestation; LV: Left ventricle, RV: Right ventricle, Chi: Hydrothorax, Pu: Pulmo, LA: Left atrium, RA: Right atrium

After all these discussion, we can conclude that:

- $\quad \mathrm{FH}$ as an isolated or associated with cardiac or other disease is a rare disorder with variable prognosis

- $\quad \mathrm{FH}$ is likely to be diagnosed more often with increasing use of antenatal ultrasound

- Cases with unilateral pleural effusion diagnosed in the $2^{\text {nd }}$ trimester are more likely to undergo spontaneous resolution

- $\quad$ Survival depends from a lung development during the fetal life and their expansion immediately after delivery if thoracentesis was successfully done during the pregnancy or immediately after delivery.

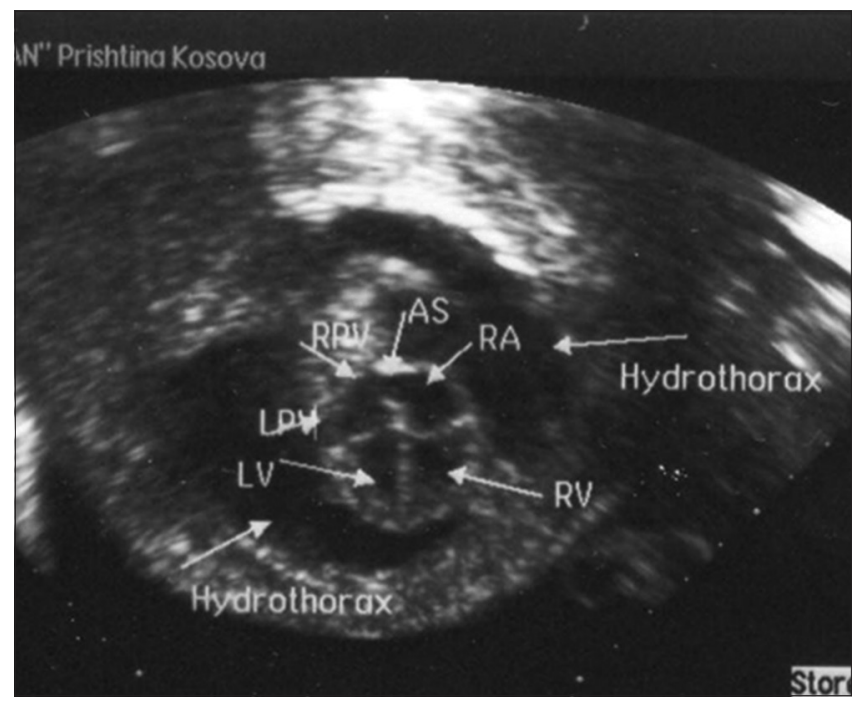

Figure 2: Four chamber view at 38 weeks of gestation hydrothorax and divided right atrium at the hydrothorax: LV: Left ventricle, Chi: Hydrothorax, Pu: Pulmo, RV: Right ventricle, RA: Right atrium, AS: Atrium sinistrum, LPV: Left pulmonary vein, RPV: Right pulmonary vein 


\section{Conclusion}

Basing on the published data, CCT is an uncommon condition which is still associated with a poor outcome. However, advances in fetal medicine, including prenatal diagnosis by itself together with the option in selected cases of scheduled fetal extraction and/or antenatal therapy, and in neonatal medicine including rapid postnatal intervention, sophisticated ventilator support are improving the prognosis of these patients and nowadays most of them are likely to survive.

\section{Availability of Data and Materials}

The datasets analyzed during the current study are available from the corresponding author on reasonable request.

\section{Authors' Contributions}

$\mathrm{HB}$ has completed obstetrician echosonographic examination; RB, RR, NZ, and AG have completed prenatal diagnosis. $R B, A V$, and AM pooled the data, analyzed the literature about hydrothorax, cor triatriatum and intrauterine infection, and wrote the manuscript. $\mathrm{RB}, \mathrm{HB}$ and $\mathrm{RiB}$ analyzed the literature about hydrothorax and cor triatriatum. All authors read and approved the final manuscript.

\section{Ethics Approval and Consent to Participate}

The authors obtained ethics approval and written informed consent. We obtained ethical approval for the data publication from Ethical Committee (EC) of the University Clinical Center of Kosovo in Prishtina, date 26.07.2018, N 1098. The authors obtained consent for publication from the patient.

\section{References}

1. Longaker MT, Laberge JM, Cansereau J, Langer J, Crombleholme TM, Callen PW, et al. Primary fetal hydrothorax:
Natural history and management. J Pediatr Surg. 1989;24:5736. http://doi.org/10.1016/s0022-3468(89)80509-3

PMid:2661800

2. Chernik V, Reed MH. Pneumothorax and chylothorax in the neonatal period. J Pediatr. 1970;76(4):624-32. http://doi. org/10.1016/s0022-3476(70)80420-6

PMid:5420804

3. Hagay Z, Reece A, Roberts A, Hobbns JC. Isolated fetal pleural effusion: A prenatal management dilemma. Obstet Gynecol. 1993;81(1):147-52.

PMid:8416451

4. Estroff JA, Parad RB, Frigoletto FD, Benacerraf BR. The natural history of isolated fetal hydrothorax. Ultrasound Obstet Gynecol. 1992;2(3):162-5. http://doi. org/10.1046/j.1469-0705.1992.02030162.x PMid:12796967

5. Nicolaides KH, Azar GB. Thoraco-amniotic shunting. Fetal Diagn Ther. 1990;5(3-4):153-4. http://doi.org/10.1159/000263586 PMid:2130840

6. Gonen R, Degani S, Shapiro I, Samberg I, Sharf M. The effect of drainage of fetal chylothorax on cardiac and blood vessel hemodynamics. J Clin Ultrasound 1993;21(4):265-8. http://doi. org/10.1002/jcu.1870210408 PMid:8478459

7. Castillo RA, Devoe LD, Falls G, Holzman GB, Hadi HA Fadel HE. Pleural effusions and pulmonary hypoplasia. Am J Obstet Gynecol. 1987;157(5):1252-5.

PMid:3318470

8. Pijpers L, Reuss A, Stewart PA, Wladmiroff JW. Noninvasive management of isolated bilateral fetal hydrothorax. Am J Obstet Gynecol. 1989;161(2):330-2. http://doi. org/10.1016/0002-9378(89)90512-7

PMid:2669488

9. Aubard Y, Derouineau I, Aubard V, Chalifour V, Preux PM Primary fetal hydrothorax: A literature review and proposed antenatal clinical strategy. Fetal Diagn Ther. 1998;13(6):325-33. http://doi.org/10.1159/000020863

PMid:9933813

10. Peleg D, Golichowski AM, Ragan WD. Fetal hydrothorax and bilateral pulmonary hypoplasia: Ultrasonic diagnosis. Acta Obstet Gynecol Scand. 1985;64(5):451-3. http://doi. org/10.3109/00016348509155166 PMid:3904318

11. Adler SP, Finney JW, Manganello AM, Best AM. Prevention of child-to-mother transmission of cytomegalovirus among pregnant women. J Pediatr. 2004;145(4):485-91. http://doi. org/10.1016/j.jpeds.2004.05.041

PMid: 15480372

12. Adler SP, Nigro G, Pereira L. Recent advances in the prevention and treatment of congenital cytomegalovirus infections. Semin Perinatol. 2007;31(1):10-8. http://doi.org/10.1053/j. semperi.2007.01.002 PMid: 17317422

13. Demmler GJ. Screening for congenital cytomegalovirus infection: A tapestry of controversies. J Pediatr. 2005;146(2):162-4. http:// doi.org/10.1016/j.jpeds.2004.11.020 PMid:15689898

14. Gerlis LM, Anderson RH. Cor triatriatum dexter with imperforate Ebstein's anomaly. Br Heart J. 1976;38(1):108-11. http://doi. org/10.1136/hrt.38.1.108

PMid: 1252290

15. Mahy IR, Anderson RH. Divison of the right atrium. Circulation. 
1998;98:2352-3.

16. Naessens A, Casteels A, Decatte L, Foulon W. A serologic strategy for detecting neonates at risk for congenital cytomegalovirus infection. J Pediatr. 2005;146(2):194-7.

PMid:15689906

17. Gallli MA, Galletti L, Schena F, Salvini L, Mosca F, Danzi GB A rare case of neonatal cyanosis due to "cor triatriatum dexter" and a review of the literature. J Cardiovasc Med. 2009;10(7):5358. http://doi.org/10.2459/JCM.0b013e32832a574f

PMid:19412123

18. Alkazaleh F, Saleem M, Badran E. Intrathoracic displacement of pleuroamniotic shunt after successful in utero treatment of fetal hydrops secondary to hydrothorax. Case report and review of the literature. Fetal Diagn Ther. 2009;25(1):40-3. http://doi. org/10.1159/000196374

\section{PMid:19176969}

19. Hidaka N, Chiba Y. Fetal hydrothorax resolving completely after a single thoracentesis: A report of 2 cases. J Reprod Med. 2007;52(9):843-8.

PMid:17939603

20. Bejiqi $R$, Retkoceri $R$, Bejiqi $H$, Zeka $N$, Kelmendi $M$ Echocardiographic diagnosis of divided right atrium cor triatriatum dextrum. Med Arh. 2010;64(5):303-4.

PMid:21287958

21. Ornoy A, Diav-Citrin O. Fetal effects of primary and secondary cytomegalovirus infection in pregnancy. Reprod Toxicol. 2006;21(4):399-409. http://doi.org/10.1016/j.reprotox.2005.02.002 PMid:16580941

22. Klam S, Bigras JL, Hudon L, Predicting outcome in primary fetal hydrothorax. Fetal Diagn Ther. 2005;20:366-70. 